\title{
Diffuse infiltrative syphilitic retinitis in an HIV-positive patient
}

\author{
Hassan Toufiqur Rahman • Steven Yeh
}

Received: 22 May 2011 / Accepted: 6 June 2011 / Published online: 26 June 2011

(C) The Author(s) 2011. This article is published with open access at SpringerLink.com

\section{Legend}

A 40-year-old HIV-positive male (CD4 count 228 cells/ul) presented with decreased vision to 20/60 OD and hand motions OS. Funduscopic examination OD revealed $2+$ vitritis with widespread intraretinal whitening, fluffy preretinal vitreous opacities, and a subhyaloidal hypopyon (a). A 4+ severe vitritis precluded retinal examination OS. PCR testing of aqueous fluid
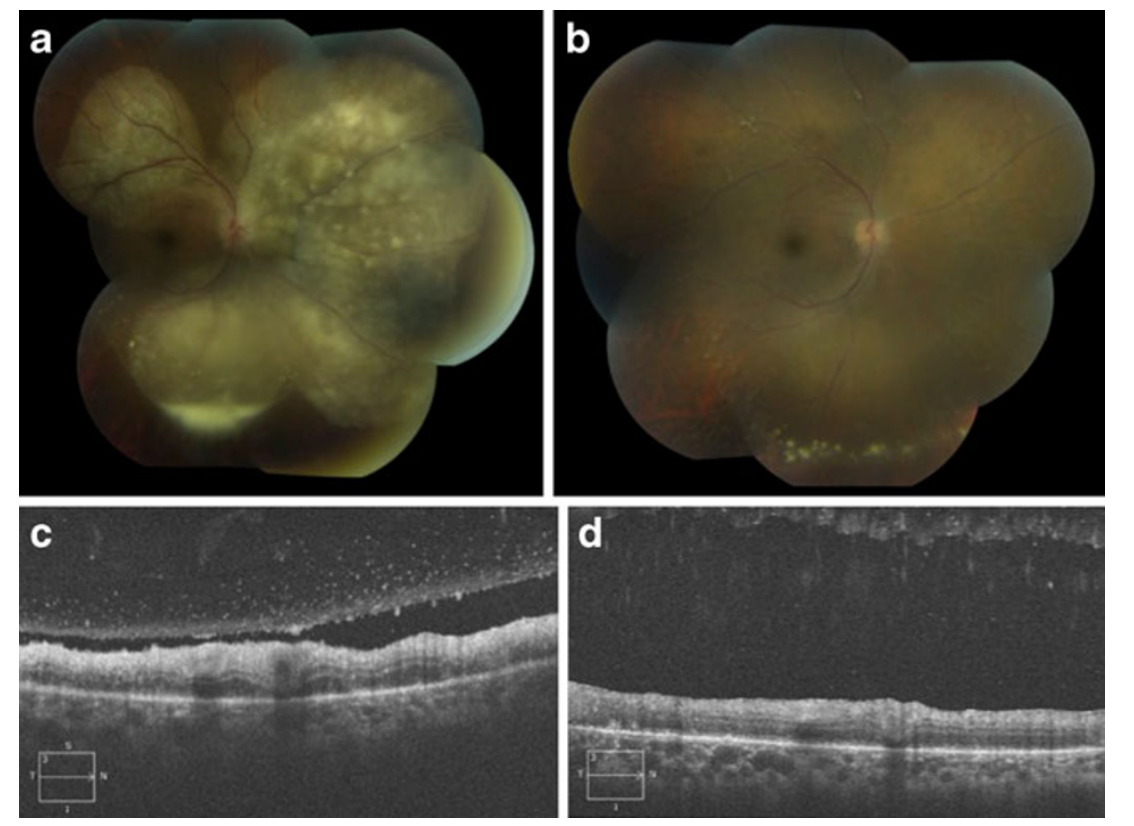

This research was funded in part by an unrestricted grant from Research to Prevent Blindness (New York, NY).

\section{H. T. Rahman $\cdot$ S. Yeh $(\triangle)$}

Emory Eye Center, Emory University School of Medicine,

1365B Clifton Rd NE,

Atlanta, GA 30322, USA

e-mail: syeh3@emory.edu

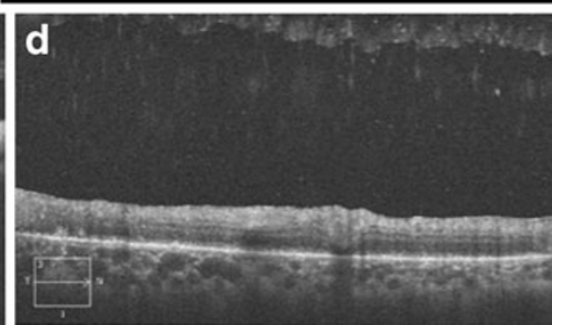

OD was negative for HSV, VZV, CMV, and toxoplasmosis DNA. Serum RPR and FTA-ABS were positive, and intravenous penicillin-G (four million units every $4 \mathrm{~h}$ ) was initiated. Three weeks later, dramatic resolution of the vitreous opacities and retinitis was observed (b). Spectral domain OCT showed decreased macular thickening, disappearance of the vitreous opacities, and restoration of the inner retinal architecture from the initial visit (c) to the final follow-up visit (d).

Open Access This article is distributed under the terms of the Creative Commons Attribution License which permits any use, distribution and reproduction in any medium, provided the original author(s) and source are credited. 